\title{
The roles of protein load test in quantitatively evaluating renal function after severe unilateral ureteral obstruction in adult rabbits
}

\author{
Changyin Wang ${ }^{1 \wedge}$, Chun Gao ${ }^{2,3 \#}$, Shun $\mathrm{Li}^{2 \#}$, Maimaiti Wasilii,4\#, Qisheng Yang ${ }^{5 \wedge}$, Linglong Jiang $^{1}$ \\ ${ }^{1}$ Department of Nuclear Medicine, Zhongnan Hospital of Wuhan University, Wuhan, China; ${ }^{2}$ Second Clinical Faculty, Medical School of Wuhan \\ University, Wuhan, China; ${ }^{3}$ Cancer Biology Research Center (Key Laboratory of the Ministry of Education), Department of Gynecologic Oncology, \\ Tongji Hospital, Tongji Medical College, Huazhong University of Science and Technology, Wuhan, China; ${ }^{4}$ Department of General Surgery, \\ People's Hospital of Changji Prefecture, Changji, China; ${ }^{5}$ Surgical Department of Emergency Center, Zhongnan Hospital of Wuhan University, \\ Wuhan, China
}

"These authors contributed equally to this work.

Correspondence to: Changyin Wang. Department of Nuclear Medicine, Zhongnan Hospital of Wuhan University, No. 169 Donghu Road, Wuhan 430071, China. Email: changyinwang@rocketmail.com; Qisheng Yang. Surgical Department of Emergency Center, Zhongnan Hospital of Wuhan University, No. 169 Donghu Road, Wuhan 430071, China. Email: yangqisheng@znhospital.com.

Background: The accuracy of dynamic renal scintigraphy in evaluating the function of hydronephrotic kidneys is controversial. This study sought to investigate the effects of ureteral obstruction on renal function and the role of the protein load test (PLT) in evaluating hydronephrotic kidneys' function.

Methods: A ureteral obstruction model was generated with New Zealand white rabbits. The baseline glomerular filtration rate (GFR) and the GFR during the PLT were measured by dynamic renal scintigraphy at weeks 6, 9, and 12 after obstruction and the renal reserve GFRs were calculated. The renal GFR differences between different time points and between the PLT and baseline status were compared.

Results: (I) Both the baseline GFRs $(\mathrm{t}=11.287, \mathrm{P}=0.000)$ and the GFRs during the PLTs $(\mathrm{t}=16.235$, $\mathrm{P}=0.000$ ) of the hydronephrotic kidneys were significantly lower than those of the contralateral kidneys. (II) The baseline GFRs of the obstructed kidneys were not significantly different 6, 9, and 12 weeks after obstruction ( $\mathrm{F}=0.122, \mathrm{P}=0.887$ ), but their net reserve $\mathrm{GFRs}(\mathrm{F}=8.419, \mathrm{P}=0.004)$ and relative reserve GFRs $(\mathrm{F}=3.770, \mathrm{P}=0.049)$ gradually decreased over time. (III) There was no significant correlation between the net reserve GFRs ( $\mathrm{r}=-0.006, \mathrm{P}=0.977$ ) or the relative reserve functions $(\mathrm{r}=-0.022, \mathrm{P}=0.920)$ of the obstructed kidneys and their baseline GFRs. However, there was a significant negative correlation between the net reserve GFRs ( $\mathrm{r}=-0.590, \mathrm{P}=0.002)$ or the relative reserve functions ( $\mathrm{r}=-0.546, \mathrm{P}=0.006)$ of the obstructed kidneys and the duration of obstruction. (IV) The reserve GFRs of the obstructed kidneys were not proportional to their baseline GFRs.

Conclusions: The functional changes in hydronephrotic kidneys are not sensitively reflected by baseline GFRs. GFRs during the PLTs and the reserve GFRs play important roles in the early and accurate evaluation of the function of obstructed kidneys.

Keywords: Dynamic renal scintigraphy; glomerular filtration rate (GFR); protein load test (PLT); renal reserve function; ureteropelvic junction obstruction (UPJO)

Submitted Dec 18, 2019. Accepted for publication Mar 04, 2021.

doi: $10.21037 /$ qims-19-1060

View this article at: http://dx.doi.org/10.21037/qims-19-1060

\footnotetext{
^ ORCID: Changyin Wang, 0000-0002-8491-6272; Qisheng Yang, 0000-0001-9827-674X.
} 


\section{Introduction}

Ureteropelvic junction obstruction (UPJO) is a common urological disease (1). UPJO not only leads to hydronephrosis, which has a series of symptoms and signs, such as back or abdominal pain, abdominal distension, and difficult urination, but also affects renal function (2-5). The biggest risk of UPJO is a renal failure (2-5). Before treating ureteral obstruction, the degree of renal functional impairment and obstruction usually needs to be considered. Dynamic renal scintigraphy of nuclear medicine is a routine method for measuring split renal functions and is widely used in clinical practice. However, due to the interference of increased intrarenal pressure, dynamic renal scintigraphy is sometimes inaccurate in evaluating the true and biggest function of hydronephrotic kidneys (5). In the baseline status, dynamic renal scintigraphy can be applied to assess present filtration or secretion ability, but not actual ability, including the potential biggest function of filtration or secretion (5). Urological surgeons need to accurately assess renal function in patients with UPJO to make appropriate treatment decisions $(6,7)$.

Renal reserve function can be detected by a protein load test (PLT), which is frequently used for the early diagnosis of renal function impairment (8). In some diseases, such as diabetes (9-11), hypertension $(12,13)$, and chronic nephritis (14), renal reserve functions are frequently reduced or even lost before their baseline functions; thus, the reserve function is a more sensitive parameter than the baseline function. For these diseases, clinicians focus on understanding how much renal function has decreased. However, for UPJO, urologists not only want to know the extent to which renal function has decreased but also the remaining functions of the obstructed kidneys, especially when considering whether or not to resect an obstructed kidney. A PLT is conducive to detecting the remaining functions of obstructed kidneys, but a PLT has not been further applied to patients with UPJO in clinical practice. We investigated the effect of partial UPJO on baseline renal function and renal reserve function and evaluated the relationship between obstructed kidneys' reserve function and baseline renal function. Some characteristics were identified that differed from those of diabetic nephropathy, hypertensive nephropathy, chronic nephritis, and other diseases. Our findings are reported as follows.

\section{Methods}

\section{Animal models of UPJO}

Eight New Zealand white rabbits were provided by Wuhan University Center for Animal Experiment/ABSLIII Laboratory. All the rabbits were healthy adult male animals, aged over 8 weeks old, had normal renal function and a bodyweight of $2.12-2.67 \mathrm{~kg}$ (with a mean of $2.45 \pm$ $0.15 \mathrm{~kg}$ ). The animal model of UPJO was generated using the ureteral casing method $(5,15)$; the obstruction was unilateral and always at the upper section of the right ureter. The study was approved by the Animal Care and Use Committee of the Wuhan University Center for Animal Experiment (AUP No. 2013110).

\section{Dynamic renal scintigraphy}

The scanning apparatus was a single-photon emission computed tomography (SPECT) scanner equipped with a low-energy high-resolution collimator (Model, e.cam; Siemens product, Hoffman Estates, IL, USA). The ${ }^{99} \mathrm{Mo-}{ }^{99 \mathrm{~m}} \mathrm{Tc}$ generator was provided by Atomic High Technology Co., Ltd., Beijing, China. Diethylene triamine pentaceticacid (DTPA) was provided by Xinkesida Pharmaceutical Technology Co., Ltd., Beijing, China. The radiochemical purity of ${ }^{99 \mathrm{~m}} \mathrm{Tc}-\mathrm{DTPA}$ was more than $95 \%$. The glomerular filtration rate (GFR) was measured by dynamic renal scintigraphy at weeks 6,9 , and 12 of UPJO. The syringes under the conditions of full or empty syringe imaging were placed on a homogeneous thin board (the $\gamma$-ray attenuation rate of the board was $6 \%$ ), which was designed to immobilize the rabbits. Scanning parameters: full or empty syringe imaging, matrix $256 \times 256$, acquisition zoom 1.0 and acquisition time $60 \mathrm{sec}$; blood perfusion phase, matrix $256 \times 256$, acquisition zoom 2.67 , acquisition time $3 \mathrm{sec} /$ frame and a total of 20 frames; and renal parenchyma phase, matrix $256 \times 256$, acquisition zoom 2.67 , acquisition time $10 \mathrm{sec} /$ frame and a total of 30 frames.

\section{Measuring baseline renal function}

The rabbits fasted for more than 12 hours. The residual foods were removed at 19:00 on the day before the examination, but normal drinking water was available. At this time, the function of the animal's kidneys was at the 
baseline status. After injection with approximately $3 \mathrm{mCi}$ of ${ }^{99 \mathrm{~m}} \mathrm{Tc}-\mathrm{DTPA}$, the acquisition procedure was immediately initiated according to the above scanning parameters. For further details on the preparation method used before scanning and bolus injection, see (5).

\section{PLT}

The animals fasted overnight, and the residual foods were removed at 19:00 on the day before the examination. Before scanning, $75 \mathrm{~g}$ of compound protein foods, including $12.22 \mathrm{~g}$ of crude protein and $1.17 \mathrm{~g}$ of amino acids (lysine, cystine, and methionine), was naturally eaten by the animals as required. The animals could freely drink water but could no longer eat any other food. The duration of animal feeding was 30 to $60 \mathrm{~min}$. If the foods were not completely eaten within $60 \mathrm{~min}$, the animals' feeding was interrupted artificially. In the study, the protein load was approximately $5.4 \mathrm{~g} / \mathrm{kg}$ (at least $2.7 \mathrm{~g} / \mathrm{kg}$ ) to ensure that a saturated amount of protein was given to avoid the effect of insufficient protein load on the GFR (16). At $10 \mathrm{~min}$ before scanning, the animals were prepared for anesthesia.

${ }^{99 \mathrm{~m}}$ Tc-DTPA dynamic renal scintigraphy was performed on animals (as described above) approximately 2.5 hours after the animals began eating. For further details on the preparation method used before scanning and bolus injection, see (5). On the 1st day, the baseline GFR was measured, and on the 2 nd day (approximately $24 \mathrm{~h}$ later), the GFR during the PLT was measured. Before the imaging agent's injection, the same acquisition parameters as those mentioned above dynamic renal scintigraphy were used; the animals were imaged for $1 \mathrm{~min}$ to calculate the kidneys' remaining radioactivity. When calculating the GFR during the PLT, a very small amount of residual radioactivity already presented in the kidneys before scanning was subtracted.

\section{Calculating the GFR and renal reserve function}

A composite image from 2-3 min was selected to outline the region of interest (ROI). The renal ROI was delineated along the edge of the functional kidney tissue; however, the nonfunctional expanded renal pelvis (for which the renal pelvis's radioactivity was lower than the background radioactivity under the kidney) was not delineated in the renal ROI. A semilunar background ROI was outlined around the lower, outer renal margins, about $2-3$ pixels from the renal ROI. The GFR was calculated according to the Gates method (17) using the measured kidney depth. In the measurement and calculation of the GFR, various influencing factors $(5,18-23)$ were considered, and corresponding quality control was performed.

Net reserve function of kidney $(\mathrm{mL} / \mathrm{min})=\mathrm{GFR}_{\text {during PLT }}$

$(\mathrm{mL} / \mathrm{min})-\mathrm{GFR}_{\text {in the baseline status }(\mathrm{mL} / \mathrm{min})}$

Relative reserve function of kidney $(\%)=\left\{\left[\mathrm{GFR}_{\text {during PLT }}\right.\right.$ $\left.\left.(\mathrm{mL} / \mathrm{min})-\mathrm{GFR}_{\text {in the baseline status }(\mathrm{mL} / \mathrm{min})}\right] / \mathrm{GFR}_{\text {in the baseline status }(\mathrm{mL} / \mathrm{min})}\right\}$ $\times 100$

The amplitude of GFR change $(\%)=\left(\mathrm{GFR}_{\text {right }}-\right.$ $\left.\mathrm{GFR}_{\text {left }} \mid / \mathrm{GFR}_{\text {left }}\right) \times 100$

The right kidneys were obstructed, and the left kidneys were healthy.

\section{Statistical analysis}

Data were analyzed with SPSS software (version 22.0; IBM Corporation, Armonk, NY, USA). The data are presented as the mean \pm standard deviation (SD). A paired $t$-test was used in the GFR comparison between the PLT and baseline status and between the obstructed and healthy kidneys. An analysis of variance of the repeated measurement data was performed to compare the GFR and reserve function at different time points of obstruction. The Pearson method was used to analyze correlations between the renal reserve function and the baseline GFR, and the renal reserve function and obstruction duration. For the two-sided tests, the significance level was $\alpha=0.05$, and a $\mathrm{P}<0.05$ was considered statistically significant.

\section{Results}

Comparison of the GFRs in the obstructed kidneys between the PLT and the baseline status

AS Table 1 shows, the GFR during the PLT was significantly higher than the baseline GFR at week 6 of obstruction $(\mathrm{P}=0.011)$; the difference was not significant at week 9 $(\mathrm{P}>0.05)$, but the GFR during the PLT was significantly lower than the baseline GFR at week $12(\mathrm{P}=0.027)$. In relation to weeks 6,9 , and 12 , the GFR difference in the obstructed kidneys in the baseline status was not statistically significant $(\mathrm{F}=2.547, \mathrm{P}=0.114)$, but the differences in the PLT $(\mathrm{F}=5.515, \mathrm{P}=0.044)$, net reserve function $(\mathrm{F}=10.605$, $\mathrm{P}=0.002)$ and relative reserve function $(\mathrm{F}=3.969, \mathrm{P}=0.043)$ were statistically significant. Notably, from the 6 th to 12 th week of obstruction, the obstructive renal function did not decline significantly with time in the baseline status, but 
Table 1 Comparison of the GFR between the PLT and the baseline status in the obstructed kidneys (means \pm SDs)

\begin{tabular}{|c|c|c|c|c|c|c|c|c|c|}
\hline $\begin{array}{l}\text { Obstruction } \\
\text { time }\end{array}$ & $\mathrm{N}$ & \multicolumn{2}{|c|}{ GFR of the right kidney } & $\mathrm{t}$ & $P$ & \multicolumn{4}{|c|}{ Reserve function of the right kidney } \\
\hline Week 9 & 8 & $20.62 \pm 15.54$ & $21.31 \pm 16.75$ & -0.654 & 0.534 & -4.64 & 3.74 & $0.69 \pm 3.00$ & $1.66 \pm 25.36$ \\
\hline
\end{tabular}

$\mathrm{N}$, number of rabbits; GFR, glomerular filtration rate; PLT, protein load test; SD, standard deviation.

Table 2 Comparison in the amplitude of the GFR change between the PLT and the baseline status in the obstructed kidneys (means \pm SDs)

\begin{tabular}{lcccc}
\hline Obstruction time & $\mathrm{N}$ & In the baseline status (\%) & In PLT (\%) & $\mathrm{t}$ \\
\hline Week 6 & 8 & $53.7 \pm 21.7$ & $51.5 \pm 15.0$ & 0.551 \\
Week 9 & 8 & $61.6 \pm 27.6$ & $73.5 \pm 17.8$ & -3.045 \\
Week 12 & 8 & $60.7 \pm 33.9$ & $76.8 \pm 22.3$ & -3.652 \\
Weeks 6-12 & 24 & $58.7 \pm 27.1$ & $67.3 \pm 21.2$ & -3.085 \\
\hline
\end{tabular}

In obstructed kidneys relative to healthy kidneys, GFR change amplitude $(\%)=\left(\mid G_{F} R_{\text {right }}-G F R_{\text {left }} / G_{\text {GFR }}\right) \times 100$, the right kidneys were obstructed, and the left kidneys were healthy. N, number of rabbits; GFR, glomerular filtration rate; PLT, protein load test; SD, standard deviation.

Table 3 Comparison of the GFR in healthy kidneys between the PLT and the baseline status (means \pm SDs)

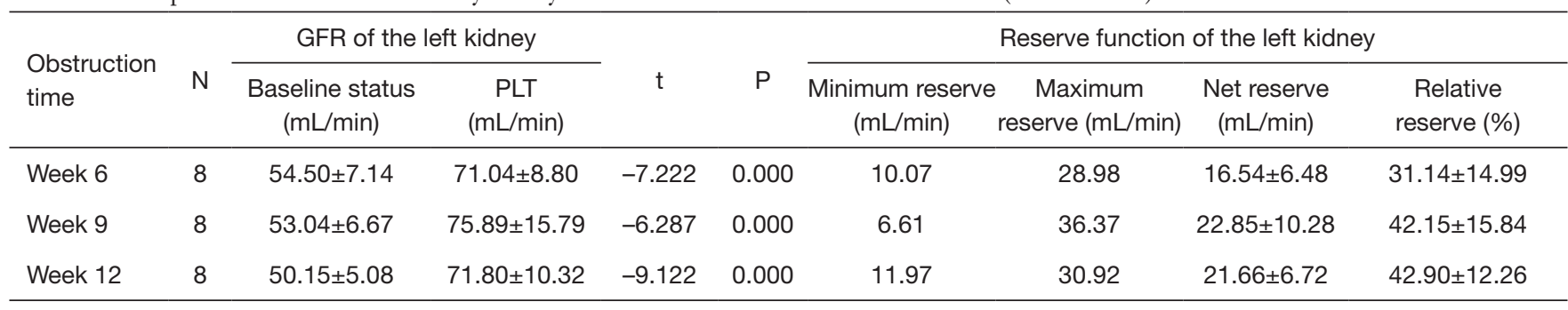

$\mathrm{N}$, number of rabbits; GFR, glomerular filtration rate; PLT, protein load test; SD, standard deviation.

the GFR during the PLT and the net and relative reserve functions gradually decreased. Thus, the GFR in the PLT and the reserve GFR appear to reveal progressive damage in obstructed kidneys more sensitively than a baseline GFR.

\section{Comparison in the amplitude of the GFR change in the obstructed kidneys between the PLT and the baseline status}

Table 2 summarizes the magnitude of the GFR reduction in the obstructed kidneys relative to the healthy kidneys. As Table 2 shows, the GFR change amplitude was different from the GFR value (see Table 1). At week 6, the GFR reduction amplitude in the obstructed kidneys in the PLT status was not higher than that in the baseline status. There was no significant difference in the magnitude of the GFR decline between the PLT and the baseline status $(\mathrm{P}>0.05)$. At the 9th and 12th weeks, the GFR reduction amplitude in the obstructed kidneys in the PLT status was significantly greater than that in the baseline status $(\mathrm{P}<0.05)$. When a healthy kidney is used as a control, the change of the GFR in an obstructed kidney in the PLT status more sensitively reflects the impairment of renal function than that in the baseline status.

\section{Comparison of the GFRs of the healthy kidneys between the PLT and the baseline status}

As Table 3 shows, the GFRs of healthy kidneys during the 
PLTs were significantly higher than those in the baseline status at weeks 6,9 , and 12 of obstruction $(\mathrm{P}=0.000)$. In relation to weeks 6,9 , and 12 of obstruction, the GFR differences in the baseline status $(\mathrm{F}=3.576, \mathrm{P}=0.095)$ and during the PLT $(\mathrm{F}=1.490, \mathrm{P}=0.298)$ were not statistically significant, nor were the differences in net reserve function $(\mathrm{F}=2.471, \mathrm{P}=0.121)$ or relative reserve function $(\mathrm{F}=2.681$, $\mathrm{P}=0.103)$. Obviously, during the 12 weeks of obstruction, the right ureteral obstruction did not significantly affect the left kidneys' baseline or reserve function.

\section{Comparison of the total GFR between the PLT and the baseline status}

As Table S1 shows, the kidneys' total GFRs during the PLTs were significantly higher than those of the baseline status at weeks 6,9 , and 12 of obstruction $(\mathrm{P}<0.05)$. In relation to weeks 6,9 , and 12 , the total GFR difference during the PLT was statistically significant $(\mathrm{F}=4.79, \mathrm{P}=0.026)$, but the total GFR was not significant in the baseline status $(\mathrm{F}=2.969$, $\mathrm{P}=0.127$ ); the difference in the relative reserve function of total kidneys was statistically significant $(\mathrm{F}=7.988, \mathrm{P}=0.005)$, but the difference in the net reserve function was not significant $(\mathrm{F}=0.895, \mathrm{P}=0.431)$. Obviously, during weeks 6 to 12 of obstruction, the right ureteral obstruction significantly affected the total GFR in the PLT and the relative reserve function but not the total GFR in the baseline status or the net reserve function.

\section{Comparison of the GFRs between obstructed and healthy kidneys}

Concerning the baseline status, the GFRs of the obstructed kidneys were significantly lower than those of the healthy kidneys at the 6th $(\mathrm{t}=8.905, \mathrm{P}=0.000)$, 9th $(\mathrm{t}=6.049, \mathrm{P}=0.001)$, and $12 \mathrm{th}(\mathrm{t}=5.186, \mathrm{P}=0.001)$ weeks of obstruction. In relation to the PLTs, the GFRs of the obstructed kidneys were significantly lower than those of the healthy kidneys at the 6 th $(\mathrm{t}=10.381, \mathrm{P}=0.000)$, 9th $(\mathrm{t}=10.681, \mathrm{P}=0.000)$, and $12 \mathrm{th}(\mathrm{t}=10.544, \mathrm{P}=0.000)$ weeks of obstruction (see Tables 1,3). The net reserve functions of the obstructed kidneys were significantly lower than those of the healthy kidneys at the 6th $(\mathrm{t}=3.928, \mathrm{P}=0.006)$, 9th $(\mathrm{t}=6.736, \mathrm{P}=0.000)$, and $12 \mathrm{th}(\mathrm{t}=11.476, \mathrm{P}=0.000)$ weeks. The difference in the relative reserve functions between the obstructed and healthy kidneys was not significant at the 6th week of obstruction $(\mathrm{t}=-1.261, \mathrm{P}=0.248)$, but the relative reserve functions of obstructed kidneys were significantly lower than those of healthy kidneys at the 9th $(\mathrm{t}=3.901, \mathrm{P}=0.006)$ and 12 th $(\mathrm{t}=4.389, \mathrm{P}=0.003)$ weeks of obstruction. The functions of obstructed kidneys, including the GFRs during the PLT and baseline status, net and relative reserve functions, generally decreased; however, the relative reserve function at 6 weeks of obstruction did not decrease significantly. Also, the obstructed kidneys' baseline function was not always reduced (see Figure 1), and the baseline function in some animals sometimes increased again (see Figure 1B).

\section{Relationship between the renal reserve function and the baseline GFR or obstruction duration}

There was no significant correlation between the net reserve function $(\mathrm{r}=0.288, \mathrm{P}=0.173)$ or the relative reserve function $(\mathrm{r}=-0.007, \mathrm{P}=0.975)$ of the healthy kidneys and the baseline GFR, and the correlation between the net reserve function $(\mathrm{r}=0.262, \mathrm{P}=0.216)$ or the relative reserve function $(\mathrm{r}=0.330, \mathrm{P}=0.115)$ of the healthy kidneys and the duration of the contralateral ureteral obstruction was not statistically significant. There was no significant correlation between the net reserve function $(r=0.012, \mathrm{P}=0.957)$ or the relative reserve function $(\mathrm{r}=-0.159, \mathrm{P}=0.457)$ of the obstructed kidneys and the baseline GFR. However, there was a strong negative correlation between the net reserve function ( $\mathrm{r}=-0.713, \mathrm{P}=0.000)$ of the obstructed kidneys and the obstruction duration, and there was a moderate negative correlation between the relative reserve function $(r=-0.504$, $\mathrm{P}=0.012)$ of the obstructed kidneys and the obstruction duration. The results showed that the assumption that the higher the baseline GFR of the obstructed kidney, the greater its reserve function was not correct. When the baseline GFR of an obstructed kidney was relatively high, it might lack reserve function (see Figure 2). Conversely, when the baseline GFR of an obstructed kidney was relatively low, it might lack reserve function (see Figure 3) or have an obvious reserve function (see Figure 4).

\section{Discussion}

Effect of ureteral obstruction on the baseline and reserve functions of obstructed kidneys

Ureteral obstruction frequently leads to renal function impairment (24). Khalil et al. (2) found that the GFRs of rabbits progressively decreased in the context of complete obstruction. Claesson et al. (4) showed that the decreased 

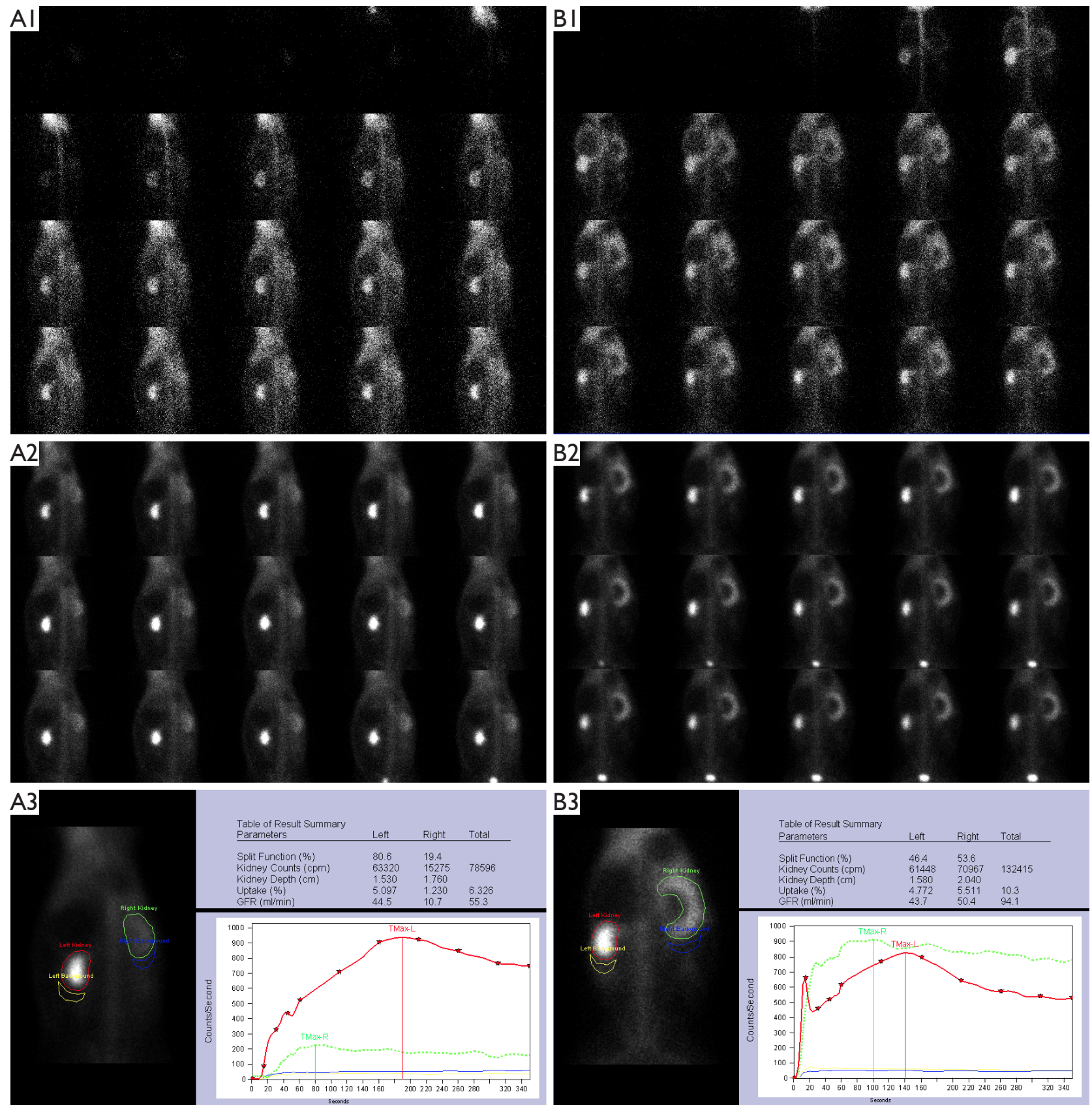

Figure 1 Dynamic renal scintigraphy of the baseline status at the 3rd and 28th days of the right ureteral obstruction for the same rabbit. (A) On the 3rd day; (B) on the 28th day. (A1,B1) The phase of blood perfusion; $(\mathrm{A} 2, \mathrm{~B} 2)$ the phase of renal function; (A3,B3) quantitative parameters and renogram curves; the right kidney curve in (A3) presented a type of low-level extension line, while that in (B3) presented a type of high-level extension line. The results showed that the right GFR $(10.7 \mathrm{~mL} / \mathrm{min})$ on the 3 rd day of obstruction was obviously lower than that of the left GFR $(44.5 \mathrm{~mL} / \mathrm{min})$; the right GFR $(50.4 \mathrm{~mL} / \mathrm{min})$ on the 28th day was slightly higher than that of the left GFR $(43.7 \mathrm{~mL} / \mathrm{min})$; the blood perfusion volume and the GFR $(50.4 \mathrm{~mL} / \mathrm{min})$ of the right kidney on the 28th day of obstruction was obviously higher than the blood perfusion and the GFR $(10.7 \mathrm{~mL} / \mathrm{min})$ on the $3 \mathrm{rd}$ day. GFR, glomerular filtration rate. 

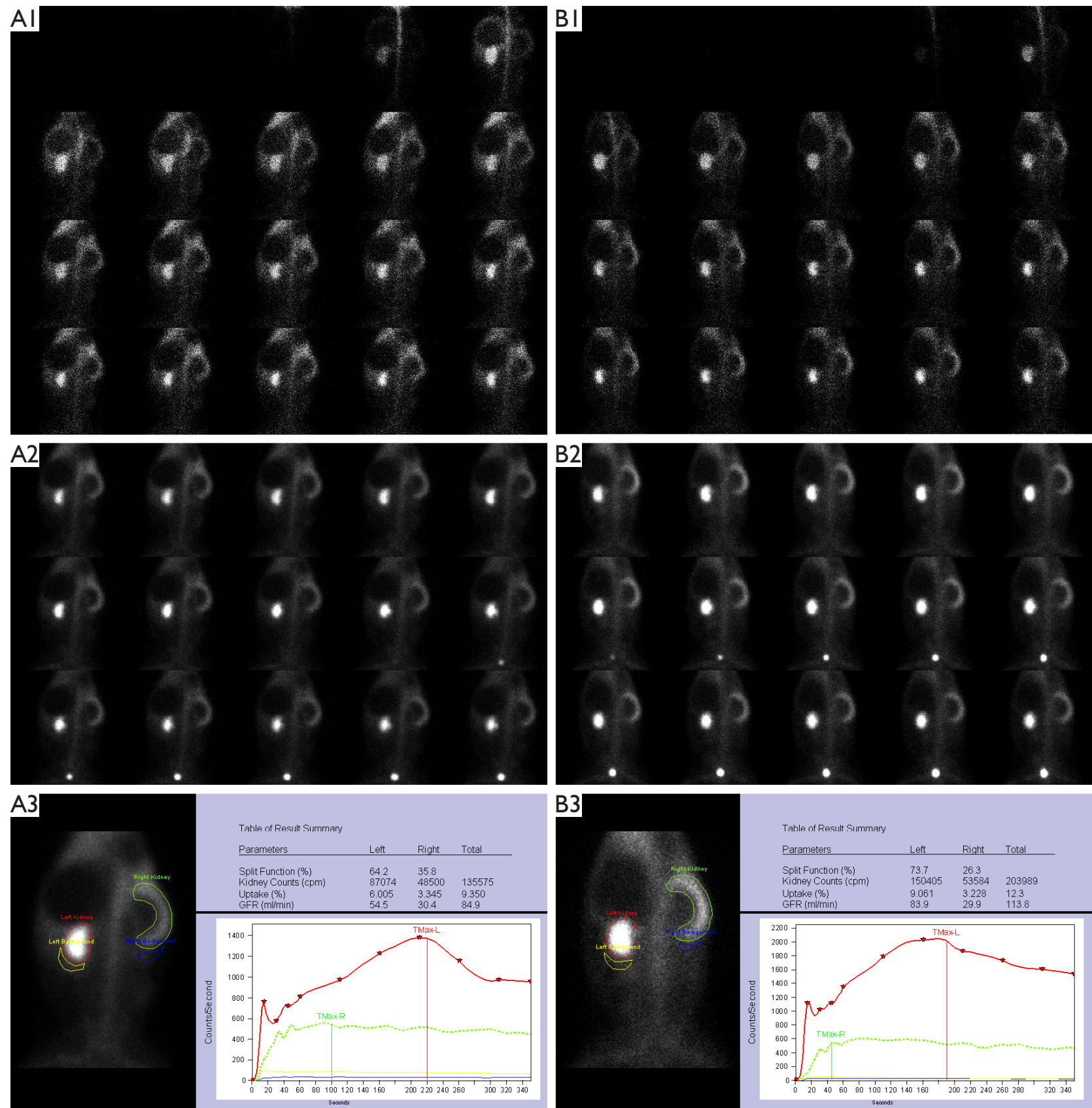

Figure 2 During the PLT and in the baseline status in the 6th week of the right ureteral obstruction in the same rabbit, dynamic renal scintigraphy. (A) Baseline status on the 42nd day of obstruction; (B) PLT on the 43rd day of obstruction. (A1,B1) The phase of blood perfusion; (A2,B2) the phase of renal function; $(\mathrm{A} 3, \mathrm{~B} 3)$ quantitative parameters and renogram curves, the right kidney curves presented a type of moderate level extension line. The results showed that the blood perfusion volume and the GFR of the right kidney in the baseline status and during the PLT were obviously lower than those of the left kidney; the GFR ( $83.9 \mathrm{~mL} / \mathrm{min})$ of the left kidney during the PLT was obviously higher than that $(54.5 \mathrm{~mL} / \mathrm{min})$ in the baseline status, and the reserve function of the left kidney was $29.4 \mathrm{~mL} / \mathrm{min}$; the GFR $(29.9 \mathrm{~mL} / \mathrm{min})$ of the right kidney during the PLT did not differ notably from that $(30.4 \mathrm{~mL} / \mathrm{min})$ in the baseline status, and the reserve function of the right kidney was $-0.5 \mathrm{~mL} / \mathrm{min}$. PLT, protein load test; GFR, glomerular filtration rate. 

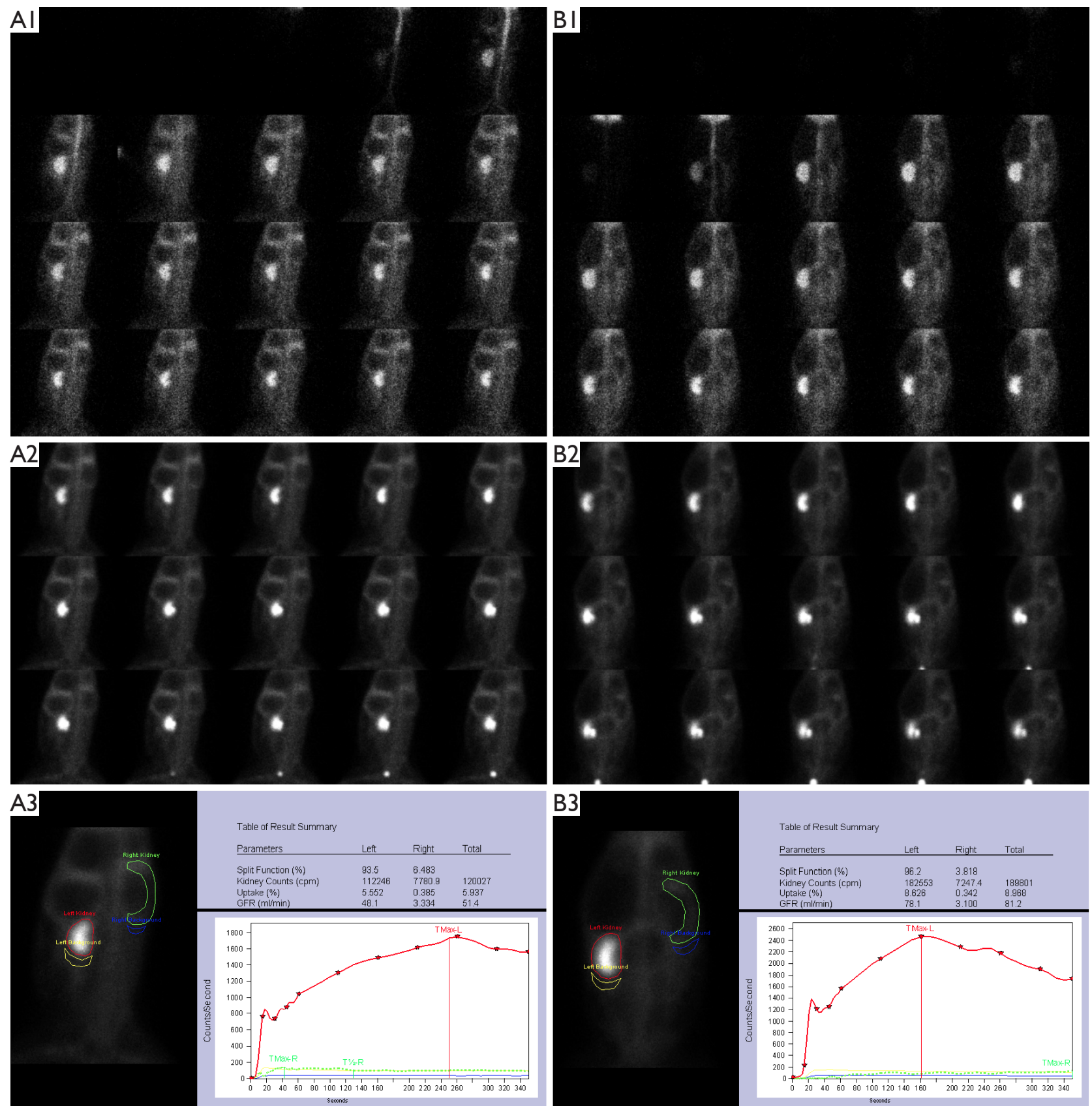

Figure 3 During the PLT and in the baseline status at the 12th week of the right ureteral obstruction in the same rabbit, dynamic renal scintigraphy. (A) Baseline status on the 82 nd day of obstruction; (B) PLT on the 83 rd day of obstruction. (A1,B1) The phase of blood perfusion; $(\mathrm{A} 2, \mathrm{~B} 2)$ the phase of renal function; $(\mathrm{A} 3, \mathrm{~B} 3)$ quantitative parameters and renogram curves; the right kidney curve in $(\mathrm{A} 3)$ presents a type of low level, descending, and that in (B3) presents a type of low-level extension line. The results showed that the blood perfusion volume and GFR of the right kidneyin the baseline status and during the PLT were obviously lower than those of the left kidney; the GFR $(78.1 \mathrm{~mL} / \mathrm{min})$ of the left kidney during the PLT was obviously higher than that $(48.1 \mathrm{~mL} / \mathrm{min})$ in the baseline status, and the reserve function of the left kidney was $30.0 \mathrm{~mL} / \mathrm{min}$; the GFR $(3.10 \mathrm{~mL} / \mathrm{min})$ of the right kidney during the PLT did not differ notably from that $(3.33 \mathrm{~mL} / \mathrm{min})$ in the baseline status, and the reserve function of the right kidney was $-0.23 \mathrm{~mL} / \mathrm{min}$. PLT, protein load test; GFR, glomerular filtration rate. 

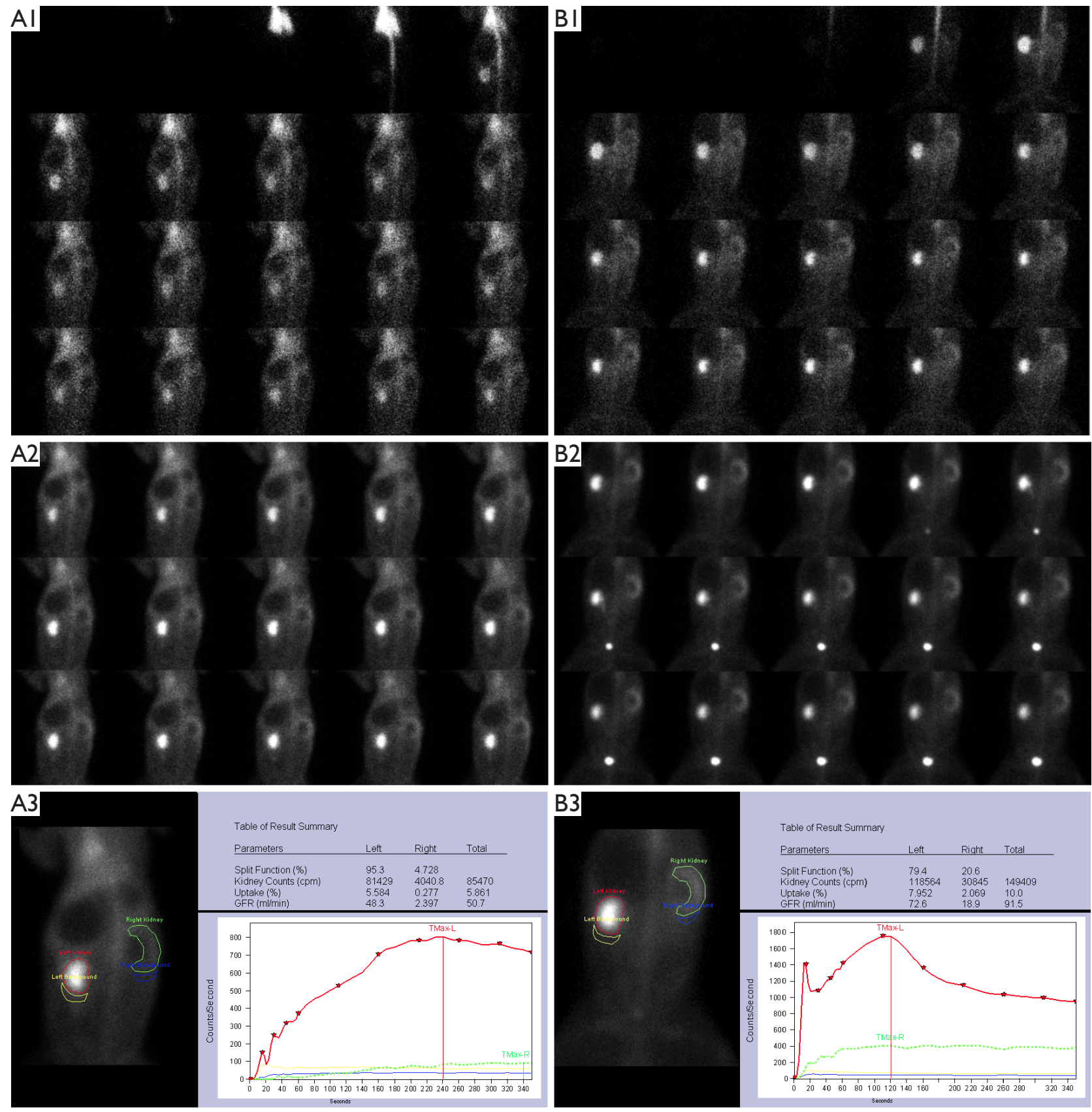

Figure 4 During the PLT and in the baseline status at the 6th week of the right ureteral obstruction in the same rabbit, dynamic renal scintigraphy. (A) Baseline status on the 42nd day of obstruction; (B) PLT on the 43rd day of obstruction. (A1,B1) The phase of blood perfusion; $(\mathrm{A} 2, \mathrm{~B} 2)$ the phase of renal function; $(\mathrm{A} 3, \mathrm{~B} 3)$ quantitative parameters and renogram curves, the right kidney curve in $(\mathrm{A} 3)$ presents a type of low level, slowly rising, and that in (B3) presents a type of low-level extension line. The results showed that the blood perfusion volume and GFR of the right kidney in the baseline status and during the PLT were obviously lower than those of the left kidney; the GFR $(72.6 \mathrm{~mL} / \mathrm{min})$ of the left kidney during the PLT was obviously higher than that $(48.3 \mathrm{~mL} / \mathrm{min})$ in the baseline status, and the reserve function of the left kidney was $24.3 \mathrm{~mL} / \mathrm{min}$; the GFR $(18.9 \mathrm{~mL} / \mathrm{min})$ of the right kidney during the PLT was obviously higher than that $(2.397 \mathrm{~mL} / \mathrm{min})$ in the baseline status, and the reserve function of the right kidney was $16.5 \mathrm{~mL} / \mathrm{min}$. PLT, protein load test; GFR, glomerular filtration rate. 
GFRs of newborn rats' obstructed kidneys did not reduce further from 6 weeks to 1 year after partial obstruction. Wang et al. (25) found that the baseline GFRs of obstructed kidneys of rabbits decreased drastically at week 1 after partial obstruction and then tended to maintain a stable status until the 8 th week. In the present study, we observed renal function changed during weeks 6 to 12 after partial obstruction and found that the obstructed kidneys' baseline GFRs tended to be stable. Changes in the baseline function will differ depending on whether the obstruction is partial or complete. However, the GFR during the PLT and the reserve function of the obstructed kidneys gradually decreased and were sometimes even lost from weeks 6 to 12. Thus, the further change in obstructive renal function is essentially a progressive impairment of the reserve function. This is similar to the changing tendency of an unresected kidney's baseline and reserve functions after a single nephrectomy (26). The present study demonstrated that the stability of the baseline GFR after the partial ureteral obstruction was maintained for a certain period by gradually depleted renal reserve function. Thus, the view that there is an absence of progressive renal damage based on the relative stability of the baseline GFR of obstructed kidneys is incorrect. Baseline renal function has an obvious disadvantage, as it does not accurately reflect the status and changing characteristics of obstructive renal function and thus cannot correctly reveal the process of obstructive renal damage. Conversely, the renal function in the PLT and the renal reserve function has obvious advantages.

\section{Effect of ureteral obstruction on the baseline and reserve functions of contralateral kidneys}

The acute decrease in one-sided kidney function is a factor by which the contralateral kidney's reserve function is activated in the baseline status. Regazzoni et al. (26) studied children who had one kidney resected and found that the contralateral kidney's baseline function compensated at the highest level at 2 to 6 months after surgery and then stabilized. However, in this study, the healthy kidneys' baseline and reserve functions were relatively stable, and the decrease in the obstructive kidney function did not result in an obvious initiation of reserve function or a compensatory increase in the baseline GFR in the contralateral kidneys at 12 weeks. These results differ from those reported by Regazzoni et al. (26). It may be that the obstructive renal function had not been reduced sufficiently. A longer period may be needed to observe the activation of the reserve function of healthy kidneys. We speculate that after the right ureters of the experimental rabbits were severely obstructed, the left renal function must have presented a compensatory increase. After the adult rabbits had eaten protein food, the left kidney function's compensation might be achieved by prolonging the working time of a high GFR under a protein load. However, before the next baseline GFR test, the left kidney function had returned to the baseline level again. Thus, when we performed the test of the baseline GFR, no functional compensation of the left kidney was found. If by this compensatory mechanism of the left kidney, a rabbit cannot complete the metabolism of previously eaten protein food by the next day, the left kidney's working time in the high GFR state will inevitably be further extended. If the baseline GFR were to be tested the next day, a compensatory increase in the baseline GFR of the left kidney or a decrease in the left kidney's reserve function might be found. However, this needs to be confirmed in future studies.

\section{The reserve of obstructive renal function and the induction of reserve function in the baseline status}

The baseline functions of the obstructed kidneys significantly decreased in the early stage (see Figure $1 A$ ). However, completely irreversible kidney damage did not occur (5). Fink et al. (27) found that impaired kidney function might recover well if the obstruction is relieved within 1 week. The baseline function turned into a reserve function, and the reserve function significantly increased, which was also indirectly confirmed by a later increase in the right renal function (see Figure 1B). Thus, there was a reverse change between the baseline and reserve functions in the early stage of obstruction, whereby the baseline renal function decreased and the renal reserve function increased. Afterward, the baseline function gradually increased restoratively (see Figure 1B). The reserve function necessarily decreased; thus, there was a new reverse change between baseline and reserve functions at this time whereby the baseline renal function increased, and the renal reserve function decreased. A reserve of obstructive kidney function and induction of reserve function in the baseline status was observed. When the baseline function recovered to a certain level, the gradual decline in reserve function could maintain the baseline function's relative stability. However, with the obvious decline or loss of reserve function, the baseline function could not be further stabilized and showed a tendency toward a gradual decline (see 
Figures 2,3). The renal function did not further increase during the PLT, indicating that the reserve function was activated in the baseline status. Also, the obstructed kidneys' function increased drastically in the baseline status, which indicated that its reserve function had been activated (see Figure 1B). Our study showed that the change in the obstructed kidney's reserve function was unilateral, not bilateral, which differed from findings for hypertensive nephropathy, diabetic nephropathy, and chronic nephritis (9-14). Thus, the obstructive renal reserve function's activation at the baseline status has different causes to those of other nephropathies.

\section{The supranormal baseline function of hydronephrotic kidneys}

This study detected the supranormal baseline function of hydronephrotic kidneys (see Figure $1 B$ and Figure S1). This is an incredibly new phenomenon. Previously, this phenomenon has been observed in clinical practice, but the findings have been controversial (28-31). Researchers thought such findings were impossible. Ajmi et al. (28), Moon et al. (29), and Inanir et al. (30) observed the same phenomenon; that is, that the baseline GFR in obstructed kidneys was higher than that in contralateral kidneys. However, Khan et al. (31) did not observe a similar phenomenon in the context of unilateral hydronephrosis. Moon et al. (29) speculated that the supranormal function's reason was that the background ROI was inappropriately outlined. Similarly, Inanir et al. (30) and Khan et al. (31) contended that artificial factors caused the phenomenon. It is our view that these interpretations are unreasonable. This is a natural phenomenon in which the hydronephrotic kidney's reserve function is gradually activated in the baseline status from a very low level that had decreased previously (see Figure 1A) and returns to the baseline function again (see Figure 1B). Thus, the hydronephrotic kidney's supranormal function does not truly exceed normal function; rather, it is an impairment of the reserve function.

\section{Relationship between the reserve and baseline functions of obstructed kidneys}

The results of the present study indicated that there was no correlation between the reserve and baseline functions of the obstructed kidneys. When the reserve function is decreased or lost, its level of baseline function may vary; for example, there may be a severe decrease (see
Figure $3 A$ ), a mild reduction (see Figure $2 A$ ), a normal level, or even an increase (see Figure $1 B$ ). Conversely, when the baseline function of hydronephrotic kidneys is severely decreased, its reserve function may vary. Englund et al. (32) and de Santo et al. (33) discovered a better reserve function under a markedly decreased baseline function in patients without hydronephrosis. Parida et al. (34) examined a unilateral hydronephrosis patient with a very low renal function whose renal function was significantly increased after relieving the obstruction, showing a high reserve function of the hydronephrotic kidney. In this study, we found a re-reserving obstructive kidney function phenomenon at a later period (see Figure 4A); that is, we found better reserve function under severely decreased baseline function conditions. However, EskildJensen et al. (35) did not observe any increase in renal function when a ureteral obstruction was relieved in the context of very low renal function, which shows a lack of reserve function. We observed similar phenomena in our experiments. The baseline function and the reserve function of hydronephrotic kidneys are often inconsistent. Thus, we cannot reasonably infer the reserve function according to an obstructed kidney's baseline function. Indeed, the degree of damage to the hydronephrotic kidney can only be accurately assessed if the baseline and reserved functions are measured simultaneously.

\section{Clinical significance of the PLT in evaluating the function of obstructed kidneys}

Our study showed that the normal and supranormal baseline GFRs in hydronephrotic kidneys do not indicate an absence of impairment. Reserve function and renal function in PLT are sensitive parameters that help identify renal impairment early, and promptly remind doctors to attach importance to progressive changes in renal function caused by obstruction, and adopt timely measures to treat any such patients. Additionally, a drastically declining baseline GFR in hydronephrotic kidneys is also not an indicator of severe renal impairment or lack of function. In this study, the animals' contralateral kidneys were completely normal, and their function could fulfill the baseline filtration requirements. Thus, obstructed kidneys can have a "rest" status with a very low baseline GFR, which may delay damage. At this time, the obstructed kidneys still have some reserve function and recoverability (6). If the residual function of a kidney is considered insignificant or nonfunctional based on the level of its baseline renal 
function, a step could be taken to remove the kidney surgically; however, this would be a mistake. At a certain obstruction stage, the relative stability of the baseline function cannot accurately reveal the progressive damage to an obstructed kidney. The progressively decreasing feature of the reserve function prompts clinicians to pay attention to the necessity of relieving the obstruction and protecting renal function. By detecting the renal reserve function and the renal function in PLT, we can both identify early dysfunction of obstructed kidneys and identify the hidden function of obstructed kidneys with a "resting" status. Thus, PLT has important clinical significance.

\section{Limitations of the study}

This study's main limitation was that the renal function in the PLT and the reserve function of the obstructed kidneys were not fully detected before 6 weeks of obstruction. We found that before 4 weeks of obstruction, especially in the early stages of obstruction, the pressure in the obstructed kidney was very high (5), which seriously interfered with the accurate measurement of renal function in the PLT and the reserve function, and no accurate data on reserve function could be obtained. However, after 6 weeks of obstruction, the obstructed kidneys were no longer expanding and began to retract (5), indicating a gradual decrease in intrarenal pressure. At this time, the interference of intrarenal pressure on the renal function in the PLT and the obstructed kidneys' reserve function was significantly reduced, which enabled us to obtain more accurate measurements. The above is not only a limitation of this study; it is also why we studied renal reserve function after 6 weeks of obstruction.

\section{Conclusions}

This study observed changes in the baseline and reserve renal functions from weeks 6 to 12 after severe ureteral obstruction. We found that obstructed kidneys' function progressively decreased and that this decrease mainly appeared in the reserve function and the renal function in the PLT and not in the baseline function. Essentially, the baseline function maintained certain stability at these time points by continuously depleting its reserve function. Baseline renal function is not a sensitive parameter reflecting obstructive renal damage; however, the reserve function and the renal function in the PLT are sensitive indicators. Our results showed that there was no significant correlation between the baseline and reserve functions. In hydronephrotic kidneys, a normal or supranormal baseline function frequently implies a decrease in or a lack of reserve function, and a lack of baseline function does not mean no function. Conversely, it can also imply a better reserve function at "rest" status. Thus, the reserve and renal functions in PLT are very important if renal impairment is to be accurately assessed, and remaining function is to be accurately detected under severe ureteral obstruction conditions.

\section{Acknowledgments}

We want to thank the Wuhan University Center for Animal Experiment/ABSL-III Laboratory staff for their animal management.

Funding: The Hubei Provincial Natural Science Foundation supported this work (Grants No. 2011CHB035). The funding organization had no role in the design or conduct of this research.

\section{Footnote}

Conflicts of Interest: All authors have completed the ICMJE uniform disclosure form (available at http://dx.doi. org/10.21037/qims-19-1060). The authors have no conflicts of interest to declare.

Ethical Statement: The authors are accountable for all aspects of the work in ensuring that questions related to the accuracy or integrity of any part of the work are appropriately investigated and resolved. This study was carried out following ethical standards related to the care and use of laboratory animals. This study was approved by the Animal Care and Use Committee of the Wuhan University Center for Animal Experiment (AUP No. 2013110).

Open Access Statement: This is an Open Access article distributed in accordance with the Creative Commons Attribution-NonCommercial-NoDerivs 4.0 International License (CC BY-NC-ND 4.0), which permits the noncommercial replication and distribution of the article with the strict proviso that no changes or edits are made and the original work is properly cited (including links to both the formal publication through the relevant DOI and the license). See: https://creativecommons.org/licenses/by-nc-nd/4.0/.

\section{References}

1. Groshar D, Wald M, Moskovitz B, Issaq E, Nativ O. 
Quantitative SPECT of ${ }^{99 \mathrm{~m}}$ Tc-DMSA uptake in kidneys of infants with unilateral ureteropelvic junction obstruction: assessment of structural and functional abnormalities. J Nucl Med 1999;40:1111-5.

2. Khalil KI, Shokeir AA, Wafa EW, Gad Gel-M, Helmy SA, Nour EM, Sarhan M. Renoprotection against complete unilateral ureteric obstruction: is there an ultimate choice? Arab J Urol 2012;10:199-206.

3. Lee WG, Kim JH, Kim JM, Shim KM, Kang SS, Chae HI, Choi SH. Renal uptakes of ${ }^{99 \mathrm{~m}} \mathrm{Tc}-\mathrm{MAG} 3,{ }^{99 \mathrm{~m}} \mathrm{Tc}-$ DTPA, and ${ }^{99 \mathrm{~m}}$ Tc-DMSA in rabbits with unilateral ureteral obstruction. In Vivo 2010;24:137-9.

4. Claesson G, Svensson L, Robertson B, Josephson S, Cederlund T. Experimental obstructive hydronephrosis in newborn rats. XI. A one-year follow-up study of renal function and morphology. J Urol 1989;142:1602-7.

5. Yang Q, Wang C, Gao C, Maimaiti W, Li S, Jiang L, Shen $M$, Shen Y. Does baseline renal function always decrease after unilateral ureteral severe obstruction? -experimental validation and novel findings by Tc$99 \mathrm{~m}$ diethylene triamine pentaacetate acid (DTPA) dynamic renal scintigraphy. Quant Imaging Med Surg 2019;9:1451-65.

6. Aziz MA, Hossain AZ, Banu T, Karim MS, Islam N, Sultana H, Alam MI, Hanif A, Khan AR. In hydronephrosis less than $10 \%$ kidney function is not an indication for nephrectomy in children. Eur J Pediatr Surg 2002;12:304-7.

7. Çamlar SA, Deveci N, Soylu A, Türkmen MA, Özmen D, Çapakaya G, Kavukçu S. The role of dynamic renal scintigraphy on clinical decision making in hydronephrotic children. Saudi J Kidney Dis Transpl 2017;28:76-80.

8. Sharma A, Mucino MJ, Ronco C. Renal functional reserve and renal recovery after acute kidney injury. Nephron Clin Pract 2014;127:94-100.

9. Mueller TF, Raeder J, Oettl K, Zitta S, Klausmann G, Estelberger W, Luyckx VA, Reibnegger G. Cystatin C does not detect acute changes in glomerular filtration rate in early diabetic nephropathy. Ren Fail 2008;30:21-9.

10. Guízar JM, Kornhauser C, Malacara JM, Amador N, Barrera JA, Esparza R. Renal functional reserve in patients with recently diagnosed Type 2 diabetes mellitus with and without microalbuminuria. Nephron 2001;87:223-30.

11. Raes A, Donckerwolcke R, Craen M, Hussein MC, VandeWalle J. Renal hemodynamic changes and renal functional reserve in children with type I diabetes mellitus. Pediatr Nephrol 2007;22:1903-9.

12. Zitta S, Stoschitzky K, Zweiker R, Oettl K, Reibnegger G,
Holzer H, Estelberger W. Dynamic renal function testing by compartmental analysis: assessment of renal functional reserve in essential hypertension. Nephrol Dial Transplant 2000;15:1162-9.

13. Pecly IM, Genelhu V, Francischetti EA. Renal functional reserve in obesity hypertension. Int J Clin Pract 2006;60:1198-203.

14. Rodríguez-Iturbe B, Herrera J, García R. Response to acute protein load in kidney donors and in apparently normal postacute glomerulonephritis patients: evidence for glomerular hyperfiltration. Lancet 1985;2:461-4.

15. Wang C, Gao C, Maimaiti W, Li S, Yang Q, Jiang L. The features of technetium-99m-DTPA renal dynamic imaging after severe unilateral ureteral obstruction in adult rabbits. PLoS One 2020;15:e0237443.

16. Sharma A, Zaragoza JJ, Villa G, Ribeiro LC, Lu R, Sartori M, Faggiana E, de Cal M, Virzi GM, Corradi V, Brocca A, Husain-Syed F, Brendolan A, Ronco C. Optimizing a kidney stress test to evaluate renal functional reserve. Clin Nephrol 2016;86:18-26.

17. Gates GF. Split renal function testing using Tc-99m DTPA: a rapid technique for determining differential glomerular filtration. Clin Nucl Med 1983;8:400-7.

18. Awdeh M, Kouris K, Hassan IM, Abdel-Dayem HM. Factors affecting the Gates' measurement of glomerular filtration rate. Am J Physiol Imaging 1990;5:36-41.

19. Inoue $\mathrm{Y}$, Itoh $\mathrm{H}$, Tagami $\mathrm{H}$, Miyatake $\mathrm{H}$, Asano $\mathrm{Y}$. Measurement of renal depth in dynamic renal scintigraphy using ultralow-dose CT. Clin Nucl Med 2016;41:434-41.

20. Kampa N, Wennstrom U, Lord P, Twardock R, Maripuu E, Eksell P, Fredriksson SO. Effect of region of interest selection and uptake measurement on glomerular filtration rate measured by ${ }^{99 \mathrm{~m}} \mathrm{Tc}-\mathrm{DTPA}$ scintigraphy in dogs. Vet Radiol Ultrasound 2002;43:383-91.

21. Ma G, Shao M, Xu B, Tian J, Chen Y. Glomerular filtration rate measured by ${ }^{99 \mathrm{~m}} \mathrm{Tc}-\mathrm{DTPA}$ Gates method is not significantly affected by the premature or delayed initiation of image acquisition. Quant Imaging Med Surg 2019;9:1103-9.

22. Wang C, Li S, Gao C, Maimaiti W, Yang Q, Jiang L. Influence of early bladder imaging in experimental rabbits on the quantitative determination of glomerular filtration rate by the gates method. Biomed Res Int 2020;2020:8848189.

23. Wei Y, Liu Y, Li Q, Zhang Y, Wang Q, Yang Y, Liang Y, Zhao A, Yang A, Xue J. Establishment of normal reference ranges for total and separate glomerular filtration rates in living kidney donors by Gates' method after renal 
depth measured using single-photon emission computed tomography/computed tomography. Quant Imaging Med Surg 2020;10:2297-306.

24. Schlotmann A, Clorius JH, Rohrschneider WK, Clorius SN, Amelung F, Becker K. Diuretic renography in hydronephrosis: delayed tissue tracer transit accompanies both functional decline and tissue reorganization. J Nucl Med 2008;49:1196-203.

25. Wang CY, Yang QS, Gao C, Muhemmet, Li S, Jiang LL and Tu XP. Variation features of basal glomerular filtration function in experimental rabbits with partial unilateral ureteral obstruction. The Journal of Practical Medicine 2016;32:2283-7.

26. Regazzoni BM, Genton N, Pelet J, Drukker A, Guignard JP. Long-term followup of renal functional reserve capacity after unilateral nephrectomy in childhood. J Urol 1998;160:844-8.

27. Fink RL, Caridis DT, Chmiel R, Ryan G. Renal impairment and its reversibility following variable periods of complete ureteric obstruction. Aust N Z J Surg 1980;50:77-83.

28. Ajmi S, Ben Ali K, Guezguez M, Sfar R, Nouira M. Captopril renography as a prognostic factor in obstructive hydronephrosis with preserved renal function. Rev Esp Med Nucl 2010;29:20-4.

29. Moon DH, Park YS, Jun NL, Lee SY, Kim KS, Kim JH, Yoon CH, Kang W, Lee HK. Value of supranormal function and renogram patterns on ${ }^{99 \mathrm{~m}} \mathrm{Tc}-$ mercaptoacetyltriglycine scintigraphy in relation to the extent of hydronephrosis for predicting ureteropelvic junction obstruction in the newborn. J Nucl Med 2003;44:725-31.

30. Inanir S, Biyikli N, Noshari O, Caliskan B, Tugtepe H, Erdil TY, Akpinar I, Kiyan G, Alpay H. Contradictory supranormal function in hydronephrotic kidneys: fact or artifact on pediatric MAG-3 renal scans? Clin Nucl Med 2005;30:91-6.

31. Khan J, Charron M, Hickeson MP, Accorsi R, Qureshi $\mathrm{S}$, Canning D. Supranormal renal function in unilateral hydronephrotic kidney can be avoided. Clin Nucl Med 2004;29:410-4.

32. Englund $M$, Berg U. Renal response to a protein load persists during long-term follow-up of children after renal transplantation. Transplantation 2000;70:1342-7.

33. de Santo NG, Capasso G, Malnic G, Anastasio P, Spitali L, D'Angelo A. Effect of an acute oral protein load on renal acidification in healthy humans and in patients with chronic renal failure. J Am Soc Nephrol 1997;8:784-92.

34. Parida GK, Tripathi M, Kumar K, Damle N. Objective improvement in renal function post-Dietl's crisis: Documented on renal dynamic scintigraphy. Indian J Nucl Med 2016;31:240-1.

35. Eskild-Jensen A, Munch Jørgensen T, Olsen LH, Djurhuus JC, Frøkiaer J. Renal function may not be restored when using decreasing differential function as the criterion for surgery in unilateral hydronephrosis. BJU Int 2003;92:779-82.
Cite this article as: Wang C, Gao C, Li S, Wasili M, Yang Q, Jiang L. The roles of protein load test in quantitatively evaluating renal function after severe unilateral ureteral obstruction in adult rabbits. Quant Imaging Med Surg 2021;11(8):3535-3548. doi: 10.21037/qims-19-1060 


\section{Supplementary}

Table S1 Comparison of the total GFR between the PLT and the baseline status in the bilateral kidneys (means \pm SDs)

\begin{tabular}{|c|c|c|c|c|c|c|c|c|c|}
\hline \multirow{2}{*}{$\begin{array}{l}\text { Obstruction } \\
\text { time }\end{array}$} & \multirow[b]{2}{*}{$\mathrm{N}$} & \multicolumn{2}{|c|}{ GFR } & \multirow[b]{2}{*}{$\mathrm{t}$} & \multirow[b]{2}{*}{$\mathrm{P}$} & \multicolumn{4}{|c|}{ Renal reserve function } \\
\hline & & $\begin{array}{l}\text { Baseline status } \\
\text { (mL/min) }\end{array}$ & PLT (mL/min) & & & $\begin{array}{l}\text { Minimum reserve } \\
(\mathrm{mL} / \mathrm{min})\end{array}$ & $\begin{array}{l}\text { Maximum reserve } \\
\text { (mL/min) }\end{array}$ & $\begin{array}{l}\text { Net reserve } \\
(\mathrm{mL} / \mathrm{min})\end{array}$ & $\begin{array}{c}\text { Relative } \\
\text { reserve (\%) }\end{array}$ \\
\hline Week 6 & 8 & $80.88 \pm 21.28$ & $105.92 \pm 19.94$ & -5.823 & 0.001 & 9.37 & 42.58 & $25.05 \pm 12.17$ & $34.84 \pm 24.26$ \\
\hline Week 9 & 8 & $73.66 \pm 18.50$ & $97.20 \pm 29.17$ & -5.573 & 0.001 & 8.08 & 40.12 & $23.54 \pm 11.95$ & $30.61 \pm 11.51$ \\
\hline Week 12 & 8 & $70.56 \pm 21.46$ & $89.60 \pm 25.74$ & -6.508 & 0.000 & 6.66 & 29.16 & $19.03 \pm 8.27$ & $27.93 \pm 13.56$ \\
\hline
\end{tabular}

N, number of rabbits; GFR, glomerular filtration rate; PLT, protein load test; SD, standard deviation.
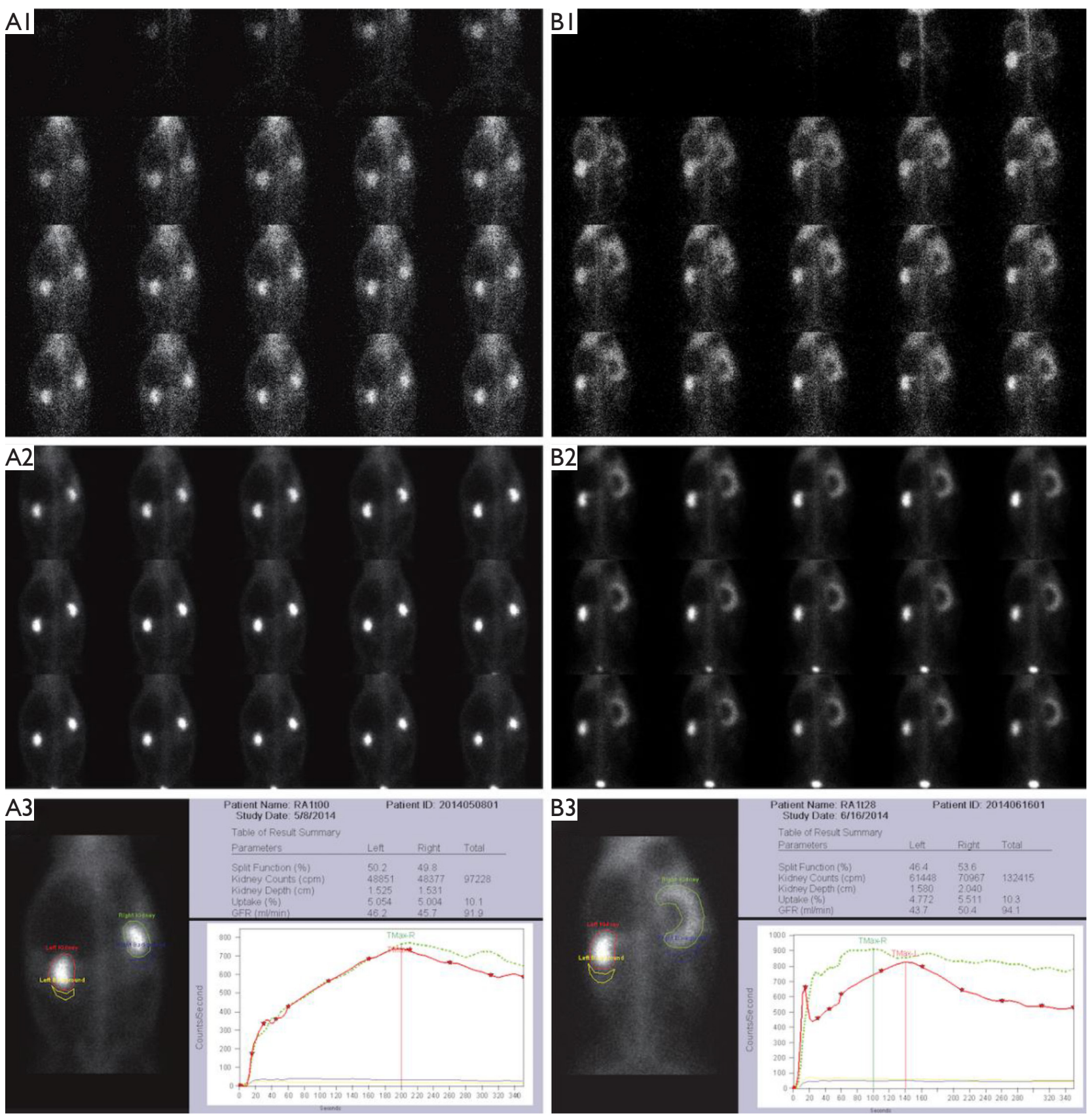

Figure S1 Dynamic renal scintigraphy in the baseline status before obstruction and on the 28th day of the right ureteral obstruction in the same rabbit. (A) Before obstruction; (B) on the 28th day of obstruction. (A1,B1) The phase of blood perfusion; (A2,B2) the renal function phase; (A3,B3) quantitative parameters and renogram curves. The results showed that the GFR $(50.4 \mathrm{~mL} / \mathrm{min})$ of the right kidney on the 28th day of obstruction was higher than the GFR $(45.7 \mathrm{~mL} / \mathrm{min})$ before obstruction, and the blood perfusion volumes and the GFRs of the bilateral kidney were similar before the obstruction. GFR, glomerular filtration rate. 